\title{
In vitro metabolism of creatinine, methylamine and amino acids by intestinal contents of normal and uraemic subjects
}

\author{
C. W. I. OWENS, Z. P. AlBUQUERQUE, AND G. M. TOMLINSON \\ From the Department of Medicine, Rayne Institute, University College Hospital Medical School, London
}

SUMMARY An original method which uses in vitro anaerobic incubation at $37^{\circ} \mathrm{C}$ followed by centrifugation, ultrafiltration, and ion exchange chromatography is described; it shows that faecal material suspended in physiological saline can destroy added creatinine. The rate of breakdown by suspensions from uraemic subjects (mean $780 \mu \mathrm{mol} \mathrm{h}-1 \mathrm{~kg}^{-1}$ SEM 70) was slightly faster than in normal subjects (mean $550 \mu \mathrm{mol} \mathrm{h}-1 \mathrm{~kg}^{-1}$ SEM 80). Methylamine concentration increased over eight hours as creatinine was metabolised and sarcosine appeared as an intermediate. The rates of these reactions varied within and between individuals and were inhibited by oxygen and centrifugation but not by oxytetracycline. Concentrations of free amino acids did not change significantly despite the formation of ammonia. This approach should be useful in studying the metabolic inter-relationships between intestinal contents and the host organism in health and disease.

Urinary concentrations of most metabolic waste products are naturally high and accumulation usually occurs in plasma once renal excretion is impaired. Two such compounds, urea and creatinine, both easily measured in plasma, have traditionally been chosen as practical guides to renal function and markers of clinical deterioration. However, for nearly 150 years a dissociation has been recognised (Bright, 1836) between the symptoms of renal failure and prevailing plasma total nitrogen concentrations. Furthermore, neither urea nor creatinine is metabolically inert; urea, for example, is metabolised by intestinal contents to ammonia (Chao and Tarver, 1953; Levenson et al., 1959) which can diffuse across the gut wall to be recycled in the liver (Richards, 1972). For a given degree of renal function the excretion of creatinine, and therefore the plasma concentration, depends on such factors as lean body mass (Fitch and Sinton, 1964; Forbes and Bruining, 1978), dietary intake of creatine (Crim et al., 1976) with a further influence being exerted by the preparation of food (Camara et al., 1951). Plasma concentrations rise slower than expected after renal shut-down in patients with chronic renal failure (Goldman, 1954; Doolan et al., 1962; Enger and Blegan, 1964) and the sum of excretion and accumulation is reduced in chronic

Received for publication 6 February 1979 renal failure (Mitch and Walser, 1978). Finally, neither substance is acutely toxic at concentrations found in advanced renal failure (Shannon, 1935; Lis and Bijan, 1970; Balestri et al., 1971).

All these observations suggest extrarenal routes of excretion with possibly further metabolism, and the present work was undertaken to develop a general method of studying any role that colonic contents might have in this particular area. It was of particular interest to discover whether creatinine could be metabolised to sarcosine and methylamine as in rat (Jones and Burnett, 1972); destruction by faecal organisms being already documented (ten-Krooden and Owens, 1975) and ileal fluid having creatinine concentrations similar to (Padovan et al., 1975) or slightly above (Chadwick et al., 1977) that of plasma. Cation exchange/ninhydrin chromatography provided the opportunity to detect ninhydrin positive metabolic products, to monitor free amino acid concentrations during incubation and relate changes to the formation of ammonia.

\section{Methods}

Faeces, free from urine, were collected from healthy adult volunteers (two male, one female) and patients (two males) suffering from chronic renal failure (plasma creatinine concentration greater than 700 $\mu \mathrm{mol} / \mathrm{l})$. Both groups had normal bowel habits and 
stool consistency. Specimens were weighed and gently homogenised in three times their weight of physiological saline (Vince et al., 1976) under oxygen free nitrogen as rapidly as possible and with minimum exposure to the air (Owens and Padovan, 1976). Creatinine was either incorporated in the physiological saline or $2 \mathrm{ml}$ of a freshly prepared concentrated solution $(35.4 \mathrm{mmol} / \mathrm{l})$ was added directly to $40 \mathrm{ml}$ of diluted stool in the incubation chamber so as to give final concentrations of between 1.7 and $1.8 \mathrm{mmol} / \mathrm{l}$. Control incubations had no added creatinine, while in experiments with oxytetracycline 10 or $20 \mathrm{mg}$ (Terramycin) were added in $1 \mathrm{ml}$ of $0.9 \%$ saline. Suspensions were incubated at $37^{\circ} \mathrm{C}$ with a stream of oxygen free nitrogen providing agitation and an anaerobic environment. Samples $(5 \mathrm{ml})$, withdrawn anaerobically from an outlet at the bottom of the incubation chamber below the level of the surrounding heated water, were taken immediately the experiment was set up $\left(t_{0}\right)$ and after one, three, six, and eight hours.

After weighing, these specimens were spun at $26000 \mathrm{~g}$ (MSE Superspeed 50) for 20 minutes at $4{ }^{\circ} \mathrm{C}$. An aliquot $(0.5 \mathrm{ml})$ of the supernatant was added to $1.7 \mathrm{ml} 0.05 \mathrm{M}$ hydrochloric acid containing $100 \mathrm{nmol}$ norleucine and kept at $-20^{\circ} \mathrm{C}$ until ultrafiltered through a Diaflo membrane (UM2, $25 \mathrm{~mm}$, molecular exclusion size 1000) supplied by Amicon B.V., Mechelaarstraat 11, Oosterhout (NB) Holland, under $1.80 \times 10^{5} \mathrm{~N} / \mathrm{m}^{2}$ nitrogen at $5{ }^{\circ} \mathrm{C}$. Ultrafiltered solutions were analysed by ion exchange chromatography (Owens and Padovan, 1975) using sodium citrate elution buffers. Amino acids, creatinine, and methylamine were identified by using authentic specimens; independent characterisation of peaks was not attempted.

Stool water was estimated by drying specimens to constant weight in weighed open screw cap bottles at $100^{\circ} \mathrm{C}$, cooling them in a desiccator and reweighing closed from air.

\section{Results}

\section{CONTROL INCUBATIONS}

In two experiments where no creatinine was added none was detected at $t_{0}$, and methylamine formation, if any, was less than $10 \mu \mathrm{mol} \mathrm{h}-1 \mathrm{~kg}^{-1}$ and beyond the reliable range of the method. Occasionally a small peak was noted which could have contributed a maximum of $2 \%$ to the area normally calculated as creatinine.

\section{CREATININE DESTRUCTION}

Initial $\left(\mathrm{t}_{0}\right)$ concentrations, determined a minimum of one hour after the addition of creatinine, were variable but averaged $81 \%$ of the calculated concentration at the start. The mean rate of breakdown $( \pm$ SEM) in normal stool was $548 \pm 76, n=5 \mu \mathrm{mol}$ $\mathrm{h}^{-1} \mathrm{~kg}^{-1}$ and relatively constant over eight hours (Fig. 1). Destruction by 'uraemic' stool was $784 \pm 67$, $\mathrm{n}=3 \mu \mathrm{mol} \mathrm{h}^{-1} \mathrm{~kg}^{-1}$ but the increased rate was not explained by variation in moisture content because mean values for the normal $(73 \% \mathrm{w} / \mathrm{w})$ and 'uraemic' specimens studied $(70.2 \% \mathrm{w} / \mathrm{w})$ were similar. The large SEM is explained in Fig. 1 where apparent

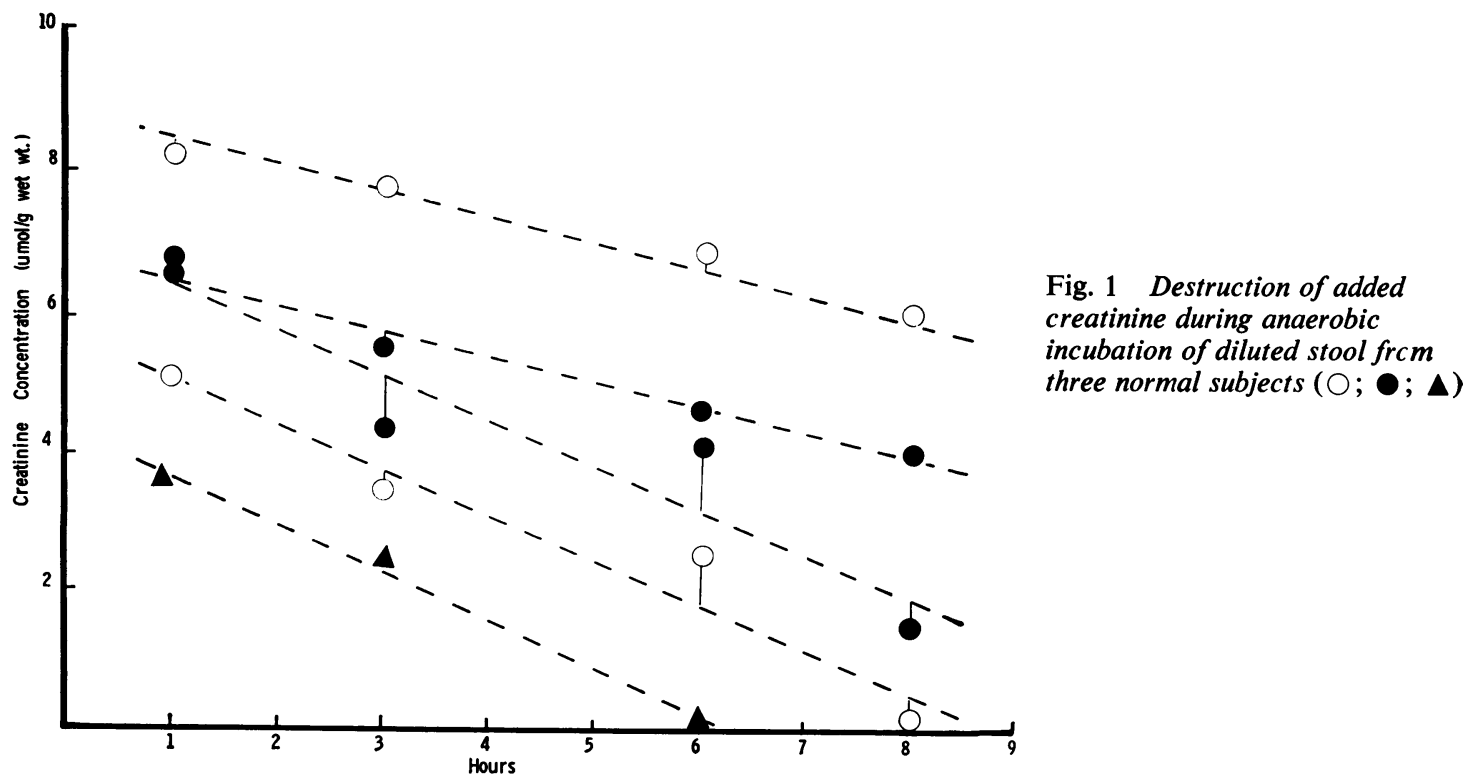


variation in rates of degradation within and between individuals is exposed.

METHYLAMINE FORMATION

This was slower than creatinine destruction and particularly so in some incubations despite normal rates of creatinine breakdown. Rates for normal and uraemic stool were similar, being $380 \pm 170$ and $350 \pm 160 \mu \mathrm{mol} \mathrm{h}^{-1} \mathrm{~kg}^{-1}$ respectively. Elution profiles did not reveal obvious alternative ninhydrin positive products to account for this discrepancy, although in occasional samples of 'uraemic' stool an unknown substance appeared in the position of norleucine. This was not separately characterised.

\section{APPEARANCE OF SARCOSINE}

Free sarcosine appeared as an intermediate (Table 1) but the times at which maximum concentrations occurred were variable. In general it was seen later (at six hours) and in greater amounts $(1.8 \mathrm{mmol} / \mathrm{kg})$ during incubation of material from uraemic subjects. There appeared to be a dissociation between the disappearance of creatinine and a slightly delayed appearance of sarcosine. The total molar concentration of methylamine, sarcosine, and creatinine was unchanged over the seven hours from $t_{1}$ to $t_{8}$ in the presence of normal stool but decreased with 'uraemic' specimens from $5 \cdot 30$ to $3 \cdot 81 \mathrm{mmol} / \mathrm{kg}$.

\section{AMINO ACID CONCENTRATIONS}

Mean free amino acid concentrations ( $\mu \mathrm{mol} / \mathrm{kg}$ original wet stool \pm SEM) during the incubation are shown in Table 2. The absence of significant changes suggests that homeostasis is maintained and the small SEM indicates that incubations are comparable and results likely to be reproducible. The slight fall in total extracellular concentration was not related to any particular amino acid.

Table 1 Mean concentrations of creatinine, sarcosine, and methylamine (mmol/kg wet stool $\pm S E M)$ during incubation of normal and 'uraemic' stool at intervals after addition of creatinine

\begin{tabular}{|c|c|c|c|c|c|c|}
\hline \multirow[b]{2}{*}{ Subject } & \multirow[b]{2}{*}{ Substance } & \multicolumn{5}{|c|}{ Incubation time (hours) } \\
\hline & & 0 & 1 & 3 & 6 & 8 \\
\hline
\end{tabular}

Table 2 Mean concentrations of free amino acids in centrifugate prepared from samples taken at intervals during anaerobic incubations $(n=11)$ of diluted stool

\begin{tabular}{|c|c|c|c|c|c|c|c|}
\hline \multirow{2}{*}{ Amino acid } & \multicolumn{6}{|c|}{ Free amino acid concentration in centrifugate ( $\mu \mathrm{mol} / \mathrm{kg})$} & \multirow[t]{2}{*}{ mean } \\
\hline & $t_{0}$ & $t_{1}$ & $t_{3}$ & $t_{6}$ & $t_{8}$ & $t_{24}$ & \\
\hline $\begin{array}{l}\text { Tau } \\
\text { Ure* } \\
\text { Asp } \\
\text { Thr } \\
\text { Ser } \\
\text { Pro }\end{array}$ & $\begin{array}{l}12 \cdot 0 \pm 4 \cdot 1 \\
268 \pm 54 \\
84 \cdot 7 \pm 10 \cdot 1 \\
24 \cdot 8 \pm 3 \cdot 3 \\
76 \cdot 7 \pm 8 \cdot 8 \\
36 \cdot 2 \pm 4 \cdot 1\end{array}$ & $\begin{array}{l}12 \cdot 3 \pm 3 \cdot 9 \\
317 \pm 47 \\
81 \cdot 9 \pm 12 \cdot 8 \\
27 \cdot 6 \pm 3 \cdot 2 \\
77 \cdot 5 \pm 8 \cdot 2 \\
78 \cdot 3 \pm 27 \cdot 0\end{array}$ & $\begin{array}{r}9 \cdot 2 \pm 1.8 \\
357 \pm 74 \\
59 \cdot 5 \pm 6.9 \\
21 \cdot 8 \pm 1 \cdot 7 \\
86.8 \pm 13 \cdot 1 \\
72 \pm 17 \cdot 5\end{array}$ & $\begin{array}{r}11 \cdot 5 \pm 3 \cdot 1 \\
431 \pm 58 \\
78 \cdot 0 \pm 12 \cdot 3 \\
18 \cdot 0 \pm 1 \cdot 9 \\
111 \cdot 3 \pm 37 \cdot 4 \\
61 \cdot 8\end{array}$ & $\begin{array}{l}9 \cdot 8 \pm 1 \cdot 7 \\
248 \pm 42 \\
61 \cdot 8 \pm 6 \cdot 8 \\
17 \cdot 3 \pm 2 \\
57 \cdot 3 \pm 7 \cdot 7 \\
33 \cdot 1 \pm 4 \cdot 3\end{array}$ & 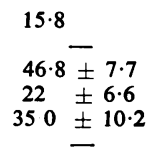 & $\begin{array}{l}11 \cdot 8 \\
324 \\
68 \cdot 8 \\
21 \cdot 9 \\
57 \cdot 4 \\
56 \cdot 3\end{array}$ \\
\hline $\begin{array}{l}\text { Glu } \\
\text { Gly } \\
\text { Ala } \\
\text { Val } \\
\text { Ile } \\
\text { Leu }\end{array}$ & $\begin{array}{l}264 \pm 62 \\
68 \cdot 2 \pm 7 \cdot 3 \\
70 \cdot 7 \pm 16 \cdot 5 \\
27 \cdot 6 \pm 9 \cdot 1 \\
21 \cdot 7 \pm 5 \cdot 5 \\
41 \cdot 2 \pm 15 \cdot 8\end{array}$ & $\begin{array}{l}293 \pm 46 \\
125 \pm 46 \cdot 3 \\
69 \cdot 3 \pm 11 \cdot 0 \\
31 \cdot 7 \pm 17 \cdot 2 \\
23 \cdot 7 \pm 9 \cdot 2 \\
32 \cdot 5 \pm 12.9\end{array}$ & $\begin{array}{l}233 \pm 34 \\
68 \cdot 6 \pm 8 \\
48 \cdot 5 \pm 4 \cdot 3 \\
27 \cdot 4 \pm 5 \cdot 7 \\
14 \cdot 3 \pm 3 \cdot 7 \\
14 \cdot 6 \pm 2 \cdot 6\end{array}$ & $\begin{array}{l}351 \pm 90 \\
90 \cdot 1 \pm 28 \cdot 7 \\
56 \cdot 7 \pm 7 \cdot 2 \\
12 \cdot 5 \pm 2 \cdot 4 \\
29 \cdot 5 \pm 6 \cdot 2 \\
19 \cdot 0 \pm 3 \cdot 9\end{array}$ & $\begin{array}{c}175 \pm 45 \\
54 \cdot 6 \pm 5 \cdot 9 \\
39 \cdot 5 \pm 4 \cdot 7 \\
16 \cdot 2 \pm 3 \cdot 1 \\
16 \cdot 1 \pm 3 \cdot 4 \\
24 \cdot 3 \pm 7 \cdot 1\end{array}$ & $\begin{array}{r}283.6 \pm 20 \\
40.9 \pm 7.8 \\
61.4 \pm 5.7 \\
18.7 \pm 10.8 \\
38 \pm 25.2\end{array}$ & $\begin{array}{r}274 \cdot 0 \\
74 \cdot 6 \\
51 \cdot 7 \\
23 \cdot 1 \\
20 \cdot 7 \\
28 \cdot 3\end{array}$ \\
\hline $\begin{array}{l}\text { Tyr } \\
\text { Phe } \\
\text { His } \\
\text { Orn } \\
\text { Lys } \\
\text { Total† }\end{array}$ & $\begin{array}{l}32.0 \pm 8.9 \\
22.0 \pm 7.9 \\
16.1 \pm 1.7 \\
37.2 \pm 5.2 \\
30.4 \pm 3.8 \\
866\end{array}$ & $\begin{array}{l}16 \cdot 6 \pm 4 \cdot 8 \\
27 \cdot 2 \pm 9 \cdot 2 \\
21 \cdot 6 \pm 4 \cdot 4 \\
28 \cdot 2 \pm 4 \cdot 9 \\
23.8 \pm 3 \cdot 5 \\
970\end{array}$ & $\begin{array}{l}12 \cdot 4 \pm 2 \cdot 5 \\
17 \cdot 4 \pm 6 \cdot 4 \\
17 \cdot 5 \pm 2 \cdot 3 \\
29 \cdot 7 \pm 4 \cdot 2 \\
21 \cdot 3 \pm 4 \cdot 7 \\
754\end{array}$ & $\begin{array}{l}13 \cdot 3 \\
16 \cdot 2 \pm 5 \cdot 4 \\
18 \cdot 4 \pm 4 \cdot 8 \\
28 \cdot 1 \pm 2 \cdot 9 \\
25 \cdot 1 \pm 4 \cdot 4 \\
941\end{array}$ & $\begin{array}{l}8.5 \pm 1.0 \\
15.3 \pm 1.7 \\
23.9 \pm 1.9 \\
26.5 \pm 3.7 \\
579\end{array}$ & $\begin{array}{c}- \\
6.7 \pm 1.6 \\
16.0 \pm 3.5 \\
12.2 \pm 3.6 \\
597\end{array}$ & $\begin{array}{l}18 \cdot 6 \\
18 \cdot 3 \\
15 \cdot 9 \\
27 \cdot 8 \\
23 \cdot 2\end{array}$ \\
\hline
\end{tabular}

*See discussion.

†Excluding 'urea'. 
EFFECTS OF OXYTETRACYCLINE, OXYGEN, AND CENTRIFUGATION

In a control incubation creatinine was destroyed at $270 \mu \mathrm{mol} \mathrm{h}-1 \mathrm{~kg}^{-1}$; when $10 \mathrm{mg}$ oxytetracycline was added the rate was $210 \mu \mathrm{mol} \mathrm{h}-1 \mathrm{~kg}^{-1}$. In a second experiment the control and experimental rates, when $20 \mathrm{mg}$ was added, were 500 and $540 \mu \mathrm{mol}$ $\mathrm{h}^{-1} \mathrm{~kg}^{-1}$ respectively. Methylamine formation was reduced from 1200 to $730 \mu \mathrm{mol} \mathrm{h} \mathrm{h}^{-1} \mathrm{~kg}^{-1}$ in the presence of $10 \mathrm{mg}$ oxytetracycline and from 390 to $130 \mu \mathrm{mol} \mathrm{h}^{-1} \mathrm{~kg}^{-1}$ with $20 \mathrm{mg}$. Both centrifugation (producing cell-free centrifugate) and aerobic incubation reduced creatinine breakdown to less than $50 \mu \mathrm{mol} \mathrm{h}-1 \mathrm{~kg}^{-1}$ and methylamine formation to less than $10 \mu \mathrm{mol} \mathrm{h}^{-1} \mathrm{~kg}^{-1}$. In our limited number of observations oxytetracycline may increase sarcosine formation from 2 to 9 and from 1 to $10 \mu \mathrm{mol}$ $\mathrm{h}^{-1} \mathrm{~kg}^{-1}$ at low and high doses respectively.

During aerobic incubation there was considerable increase in total free amino acid concentrations from, for example, 0.79 to $3.80 \mu \mathrm{mol} / \mathrm{kg}$ at six hours, comprising mainly increases of alanine by 30-fold, glycine by seven-fold, serine by five-fold and glutamate by four-fold.

\section{AMMONIA FORMATION}

This is depicted in Fig. 2 and was derived by estimation of the 'ammonia' peak on the chromatographic profile using ammonium chloride as a standard. The reaction was not accompanied by a reduction in concentration of any particular free amino acid.

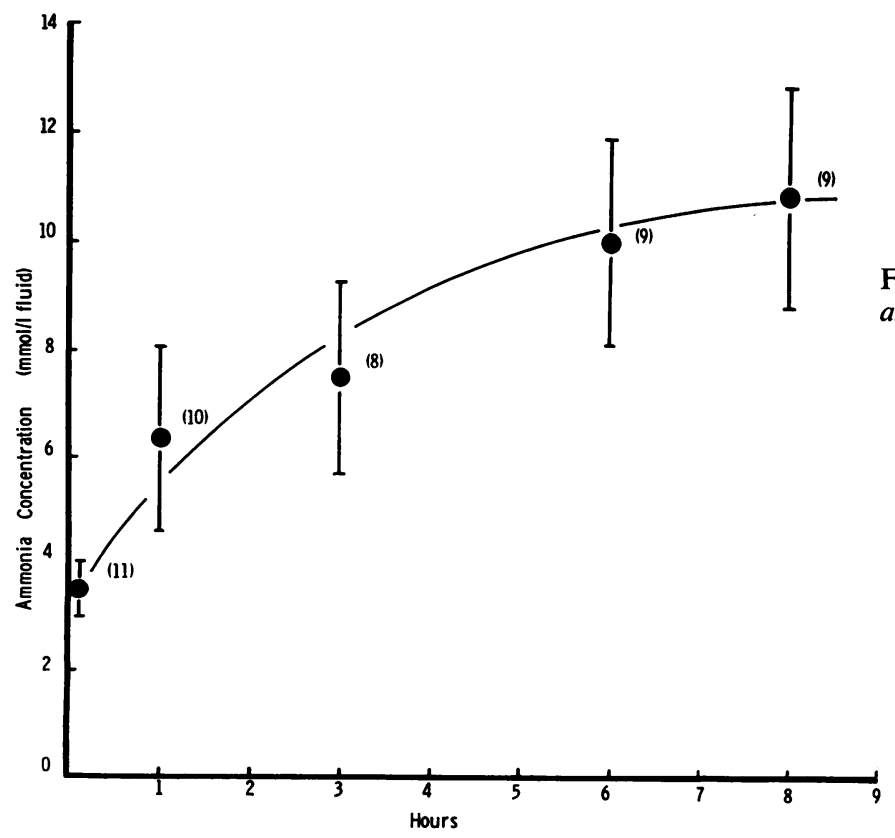

CREATININE IN ILEAL FLUID AND PLASMA Destruction of creatinine in the large bowel can occur only if effective delivery to this site is achieved. Ileal effluent is the most likely vehicle and observations on 10 patients with ileostomies, three who also had chronic renal failure, confirm this. In the normal subjects mean plasma creatinine concentration (picrate method) was $97 \pm 9 \mu \mathrm{mol} / 1$ and that in the ileal fluid (ion-exchange chromatography) was $140 \pm 104 \mu \mathrm{mol} / 1$ giving a fluid:plasma ratio of 1.44 . In the three cases with renal impairment mean plasma concentrations of $221 \pm 15,266 \pm 9$ and $830 \mu \mathrm{mol} / \mathrm{l}$ were associated with simultaneous fluid concentrations of $335 \pm 107,332 \pm 22$ and 370 $\mu \mathrm{mol} / 1$ giving fluid:plasma ratio of $1 \cdot 51,1.24$ and 0.44 respectively.

\section{Discussion}

During acute oliguric renal failure in a previously healthy subject plasma creatinine concentration usually rises by about $0.30 \mathrm{mmol} / \mathrm{l}$ each day which accords with the distribution of a normal daily production of about $10 \mathrm{mmol}$ through approximately 401 of body water. If there is pre-existing renal failure the accumulation is slower (Doolan et al., 1962; Enger and Blegen, 1964), which cannot be explained by reduced muscle mass alone (Goldman, 1954). Isotope dilution studies confirm a discrepancy between production of creatinine and the sum of its accumulation and excretion (Jones and Burnett, 1974) with between 16 and $66 \%$ being
Fig. 2 Formation of ammonia during anaerobic incubation of diluted stool 
metabolised to compounds such as sarcosine, methylamine, and carbon dioxide. Finally rat faecal microflora have an inducible ability to destroy creatinine (Jones and Burnett, 1972), which points to gut playing a role in the 'creatinine deficit'.

We find creatinine can be degraded anaerobically by human intestinal contents to products resembling those found in similar experiments using rat faeces or following isotope studies in man. The mean rate of degradation by material from uraemic subjects was slightly faster than in normal subjects, with the reaction occasionally proceeding to completion. More rapid destruction by 'uraemic' stool is compatible with induction of 'creatinase' activity in man like rat (Jones and Burnett, 1972). If, for example, terminal colon contains the faecal output for one day, say $150 \mathrm{~g}$, then these contents alone in uraemia could destroy about $2.9 \mathrm{mmol}$ or $325 \mathrm{mg}$ daily, which seems a reasonable estimate, in that it represents $66 \%$ of the mean loss calculated by Jones and Burnett (1974), not allowing for degradation achieved by intestinal contents elsewhere.

This metabolic 'sink' requires that creatinine reaches the colon. Picrate based colorimetric analysis of intestinal perfusate (Jones and Burnett, 1974) shows that concentrations increase along the gut and finally reach about $50 \%$ of plasma concentrations in the colon, and about $25 \%$ of an oral load of creatinine in a normal subject reaches the colon (Dominguez and Pomerene, 1945). The more specific method used here of ion-exchange chromatography after removal of chromogens finds creatinine in ileal fluid of normal and uraemic subjects in a concentration similar to plasma, and in varying concentrations in the faecal dialysate of uraemics but not in that from normal subjects (Owens and Padovan, 1979). A daily output (say $1.5 \mathrm{l}$ ) of normal or 'moderately uraemic' ileal fluid might provide the colon with between 0.15 and $1.20 \mathrm{mmol}$ creatinine, hence the absence in normal stool and variable presence in uraemia as the destructive process is overloaded. Although the capacity for degradation appears to exceed the irreversible metabolism of endogenous creatinine calculated by Mitch and Walser (1978), this is appropriate, as consumption of creatinine from dietary sources must be achieved before effects are seen on that generated endogenously.

Several bacteria have an inducible capacity to destroy creatinine with formation of sarcosine. Creatinine enriched aerobic cultures of soil bacteria (Miller and Dubos, 1936) and Arthrobacter ureafaciens (Krebs and Eggleston, 1939) produce urea and ammonia from either creatine or creatinine. Sarcosine and glycine are intermediates, and whole cells, as found here, appear to be mandatory (Akarnatsu and Miyashita, 1951). Pseudomonads also produce sarcosine (Roche et al., 1950), presumably by first forming creatine from creatinine (creatinine hydrolase) (Kaplan and Naugler, 1974), and then the sarcosine with urea (creatine amidinohydrolase). The anaerobic formation of methylamine, however, is not described but it is formed with glyoxylate during oxidative deamination of sarcosine by a pig kidney D-amino acid oxidase (Naoi and Yagi, 1976). Amino acid oxidases occur in microorganisms (Stumpf and Green, 1944; Norton et al., 1963); they usually require molecular oxygen as a hydrogen acceptor but electron accepting dyes can be substituted. Under anaerobic conditions, the glyoxylate could be transaminated by alanine (which falls during the formation of methylamineTable 2) to form glycine and pyruvate. Decarboxylation of pyruvate would yield $\mathrm{CO}_{2}$ and acetaldehyde, which reduces to ethanol (a well-established anaerobic fermentation product). The concomitant formation of NADP then would enable reoxidation of the flavine adenine dinucleotide prosthetic group of the amino-acid oxidase, so obviating the need for molecular oxygen.

The failure of oxytetracycline to inhibit creatinine destruction could be related to brevity of exposure, bacteriostatic properties, final concentration, or microbiological resistance. However, other workers have noted the inability of antibiotics to modify creatinine metabolism.

Sarcosine appearing as an extracellular intermediate explains the appearance of labelled sarcosine in the urine and plasma after injection of ${ }^{14} \mathrm{CH}_{3}$-creatinine (Jones and Burnett, 1974) but raises the possibility that sarcosine is either absorbed from the colon or is also produced in alternative sites, such as terminal ileum or tissue. It also means that more than one bacterial species can be involved in the conversion of creatinine to methylamine.

Unexplained shortcomings in the method include an apparent rise in creatinine concentration after one hour in some incubations. This might be explained by sampling and analytical errors or be attributable to unknown factors interfering with the assay of early $\left(t_{0}\right)$ samples. Similarly, differences in concentrations found among the various incubations (Fig. 1) may have been caused by variable nonspecific binding or interference with the assay. At least $60 \%$ of the mean $19 \%$ shortfall in the creatinine detected at $t_{0}$ can be explained by assuming that destruction occurred during mixing and centrifugation at the subsequently determined rate. The peak recognised as urea probably represents an alternative substance because it did not decrease during the formation of ammonia (Wrong, 1971). This indirectly confirms the absence of urea and therefore the findings with the Conway technique 
(Wilson et al., 1968) and ion-exchange chromatography (Owens and Padovan, 1975).

The unchanging mean total molar concentration of creatinine and methylamine during incubation of normal stool (Table 1) indicates stoichiometric conversion mol for mol but the rate of the methylamine formation seems slower than creatinine breakdown $(P=0.05$, Student's paired $t$ test $)$. This may represent an intracellular lag or, in the uraemic subject, the formation of alternative products such as N-methyl hydantoin (Szulmajster, 1958; tenKrooden and Owens, 1975) or even methyl guanidine (van Eyk et al., 1968). Methylamine appears to be stable, for in three 24 hour incubations (two anaerobic and one aerobic) concentrations did not alter despite changes in amino acid levels. As an end product of creatinine metabolism, concentrations did not rise during control incubations and never became greater than expected from the creatinine destroyed. The extent or significance of its absorption from the colon is unknown in uraemia where only small amounts appear in the plasma (Simenhoff et al., 1963), possibly because of enzymic oxidation. It apparently does not accompany diand tri-methylamine in duodenal aspirate (Simenhoff et al., 1976) or breath (Simenhoff et al., 1977).

The method appears to be bacteriologically valid, in that amino acid concentrations fall only slightly even in the presence of oxytetracycline, indicating that homeostasis is maintained. There was good correlation $(P<0.001)$ with amino acid concentrations reported for centrifugate prepared from freshly passed stool (Owens and Padovan, 1976). Large increases in alanine seen during aerobic incubation may have been secondary to transamination of pyruvate generated instead of the lactate expected in the anaerobic system. Glycine (Akamatsu and Miyashita, 1951) did not appear as an intermediate in methylamine formation and no changes occurred to account for the formation of ammonia, which was found to occur in a manner identical to that reported by Vince et al. (1976) using the ammonia electrode as a method of assay.

In conclusion, anaerobic incubation of diluted stool seems a valid method of studying metabolism of compounds by intestinal contents. It is hoped that this approach will be useful in the elucidation of 'deficits' known and unknown and subsequently in the discovery of relevant 'uraemic toxins'.

\section{References}

Akamatsu, S., and Miyashita, R. (1951). Bacterial decomposition of creatinine. III. The pathway of creatine decomposition. Enzymologia, 15, 173-176.

Balestri, P. L., Rindi, P., and Biagini, M. (1971). Chronic urea intoxication in dogs. Experientia, 27, 811-812.
Bright, R. (1836). Cases and observations, illustrative of renal disease accompanied with the secretion of albuminous urine. Guy's Hospital Reports, 1, 338-379.

Camara, A. A., Arn, K. D., Reimer, A., and Newburgh, L. H. (1951). The twenty-four hourly endogenous creatinine clearance as a clinical measure of the functional state of the kidneys. Journal for Laboratory and Clinical Medicine, 37, 743-763.

Chadwick, V. S., Jones, J. D., Debongnie, J.-C., Gaginella, T., and Phillips, S. F. (1977). Urea, uric acid and creatinine fluxes through the small intestine of man (Abstract). Gut, 18, A944.

Chao, F. C., and Tarver, H. (1953). Breakdown of urea in the rat. Proceedings of the Society for Experimental Biology and Medicine, 84, 406-409.

Crim, M. C., Calloway, D. H., and Margen, S. (1976). Creatine metabolism in men: creatine pool size and turnover in relation to creatine intake. Journal of Nutrition, 106, 371-381.

Dominguez, R., and Pomerene, E. (1945). Recovery of creatinine after ingestion and after intravenous injection in man. Proceedings of the Society for Experimental Biology and Medicine, 58, 26-28.

Doolan, P. D., Alpen, E. L., and Theil, G. B. (1962). A clinical appraisal of the plasma concentration and endogenous clearance of creatinine. American Journal of Medicine, 32, 65-79.

Enger, E., and Blegen, E. M. (1964). The relationship between endogenous creatinine clearance and serum creatinine in renal failure. Scandinavian Journal of Clinical and Laboratory Investigation, 16, 273-280.

van Eyk, H. G., Vermaat, R. J., Leijnse-Ybema, H. J., and Leijnse, B. (1968). The conversion of creatinine by creatininase of bacterial origin. Enzymologia, 34, 198-202.

Fitch, C. D., and Sinton, D. W. (1964). A study of creatine metabolism in diseases causing muscle wasting. Journal of Clinical Investigation, 43, 444-452.

Forbes, G. B., and Bruining, G. J. (1978). Urinary creatinine excretion and lean body mass. American Journal of Clinical Nutrition, 29, 1359-1366.

Goldman, R. (1954). Creatinine excretion in renal failure. Proceedings of the Society for Experimental Biology and Medicine, 85, 446-448.

Jones, J. D., and Burnett, P. C. (1972). Implication of creatinine and gut flora in the uremic syndrome: Induction of "creatinase" in colon contents of the rat by dietary creatinine. Clinical Chemistry, 18, 280-284.

Jones, J. D., and Burnett, P. C. (1974). Creatinine metabolism in humans with decreased renal function: Creatinine deficit. Clinical Chemistry, 20, 1204-1212.

Kaplan, A., and Naugler, D. (1974). Creatinine hydrolase and creatine amidinohydrolase: 1. Presence in cell-free extracts of Arthrobacter ureafaciens. Molecular and Cellular Biochemistry, 3, 9-15.

Krebs, H. A., and Eggleston, L. V. (1939). Bacterial urea formation. Metabolism of Corynebacterium ureafaciens. Enzymologia, 7, 310-320.

Levenson, S. M., Crowley, L. V., Horowitz, R. E., and Malm, O. J. (1959). The metabolism of carbon-labeled urea in the germfree rat. Journal of Biological Chemistry, 234, 2061-2062.

Lis, A. W., and Bijan, R. (1970). The function of creatinine. Physiological Chemistry and Physics, 2, 293-299.

Miller, B. F., and Dubos, R. (1936). Enzyme for decomposition of creatinine and its action on the 'apparent creatinine' of blood. Proceedings of the Society for Experimenta Biology and Medicine, 35, 335-336.

Mitch, W. E., and Walser, M. (1978). A proposed mechanism for reduced creatinine excretion in severe chronic renal failure. Nephron, 21, 248-254. 
Naoi, M., and Yagi, K. (1976). Oxidation of sarcosine and $\mathrm{N}$-alkyl derivatives of glycine by $\mathrm{D}$-amino acid oxidase. Biochemica et Biophysica Acta, 438, 61-70.

Norton, J. E., Bulmer, G. S., and Sokatch, J. R. (1963). The oxidation of $D$-alanine by cell membranes of Pseudomonas aeruginosa. Biochemica et Biophysica Acta, 78, 136-147.

Owens, C. W. I., and Padovan, W. (1975). Quantitative method for estimating fecal amino acids. Clinical Chemistry, 21, 1437-1440.

Owens, C. W. I., and Padovan, W. (1976). Limitations of ultra-centrifugation and in vivo dialysis as methods of stool analysis. Gut, 17, 68-74.

Owens, C. W. I., and Padovan, W. (1979). Faecal methylamine in normal and uraemic subjects. Clinical Science, 56, 508-512.

Padovan, W., Owens, C. W. I., and Ferguson, R. (1975) Creatinine and amino acid profiles of ileal and faecal fluids (Abstract). Clinical Science and Molecular Medicine, 49, 27P.

Richards, P. (1972). Nutritional potential of nitrogen recycling in man. American Journal of Clinical Nutrition, 25, 615-625.

Roche, J., Lacombe, G., and Girard, H. (1950). Sur la spécificité de certaines déguanidases bactériennes génératrices d'urée et sur l'argininedihydrolase. Biochemica et Biophysica Acta, 6, 210-216.

Shannon, J. A. (1935). The renal excretion of creatinine in man. Journal of Clinical Investigation, 14, 403-410.

Simenhoff, M. L., Asatoor, A. M., Milne, M. D., and
Zilva, J. F. (1963). Retention of aliphatic amines in uraemia. Clinical Science, 25, 65-77.

Simenhoff, M. L., Saukkonen, J. J., Burke, J. F., Wesson, L. G., and Schaedler, R. W. (1976). Amine metabolism and the small bowel in uraemia. Lancet, 2, 818-821.

Simenhoff, M. L., Burke, J. F., Saukkonen, J. J., Ordinario, A. T., and Doty, R. (1977). Biochemical profile of uremic breath. New England Journal of Medicine, 297, 132-135.

Stumpf, P. K., and Green, D. E. (1944). L-amino acid oxidase of Proteus vulgaris. Journal of Biological Chemistry, 153, 387-399.

Szulmajster, J. (1958). Bacterial fermentation of creatinine. I. Isolation of $\mathrm{N}$-methyl-hydantoin. Journal of Bacteriology, 75, 633-639.

Ten-Krooden, E., and Owens, C. W. I. (1975). Creatinine metabolism by Clostridium welchii isolated from human faeces. Experientia, 31, 1270.

Vince, A., Down, P. F., Murison, J., Twigg, F. J., and Wrong, O. M. (1976). Generation of ammonia from non-urea sources in a faecal incubation system. Clinical Science and Molecular Medicine, 51, 313-322.

Wilson, D. R., Ing, T. S., Metcalfe-Gibson, A., and Wrong, O. M. (1968). In vivo dialysis of faeces as a method of stool analysis. 3. The effect of intestinal antibiotics. Clinical Science, 34, 211-221.

Wrong, O. M. (1971). The role of the human colon in homeostasis. Scientific Basis of Medicine, 192-215 (see pp. 204-205). 